University of Paris, Faculty of Medicine

DEPARTMENT OF THE History OF MEDICINE AND SURGERY

A series of seven sessions on the subject 'The History of Radiology' will be held from 6 April to 25 May, 1967. The lecturers are Professor H. Fischgold, Professor A. G. R. Ledoux-Lebard, and Dr. P. Pizon, and the lectures will include: The Discovery of X-Rays, and their Significance in the Evolution of Anatomy, Radiology in France from 1896 to 1904, The History of the Radiology of the Digestive System, Radiobiology and Radiotherapy, and Neuroradiology.

\title{
UNIVERSITY OF OsLo, INSTITUTE OF HYGIENE
}

A new library of medical history has been founded at the Institute of Hygiene at the University of Oslo. The Director is Dr. Qivind Larsen, and the address is: Oslo, Gydas Vei 8, V/Majorstua, Norway. The Director would be very pleased to receive reprints of any papers on medical history and related subjects.

\section{New Medical Postage Stamp}

In honour of the first centenary of Baron Sandor Korányi, professor for internal medicine in Hungary, the Hungarian post office issued a new stamp with a portrait of Korányi.

\section{Wellcome Historical Medical Museum and Library SATURDAY OPENING}

The Wellcome Historical Medical Museum and Library (183 Euston Road, London, N.W.1.) are now open to the public on Saturdays from 9.30 a.m. to 4.30 p.m. This is in addition to the normal weekday opening (10 a.m. to 5 p.m.). The Museum and Library are closed on Bank Holidays. 